PACS 31.15.-p

\title{
V. V. Buyadzhi
}

Odessa State Environmental University, 15, Lvovskaya str., Odessa-16, 65016, Ukraine

E-mail: buyadzhivv@gmail.com

\section{ELECTRON-COLLISIONAL SPECTROSCOPY OF ATOMS AND IONS: ADVANCED ENERGY APPROACH}

\begin{abstract}
An advanced relativistic energy approach combined with a scattering theory is used to calculate the electroncollision excitation cross-sections, collision strengths for a number of multicharged ions. The relativistic many-body perturbation theory is used alongside the gauge-invariant scheme to generate an optimal Dirac-Kohn-Sham- DebyeHückel one-electron representation. The results of relativistic calculation (taking into account the exchange and correlation corrections) of the electron collision cross-sections (strengths) of excitation of the transition between the fine-structure levels $\left(2 \mathrm{P}_{3 / 2}-2 \mathrm{P}_{1 / 2}\right)$ of the ground state of F-like ions with $\mathrm{Z}=19-26$ and of the $\left[2 \mathrm{~s}^{2}{ }^{1} \mathrm{~S}-\left(2 \mathrm{~s} 2 \mathrm{p}{ }^{1} \mathrm{P}\right)\right]$ transition in the $\mathrm{B}-$ like $\mathrm{O}^{4+}$ are presented and analysed.
\end{abstract}

\section{Introduction}

Electron-collisional spectroscopy of atoms and multicharged ions is one of the most fast developing branches of modern atomic spectroscopy. The properties of laboratory and astrophysical plasmas have drawn considerable attention over the last decades [1-15]. It is known that multicharged ions play an important role in the diagnostics of a wide variety of plasmas. Similar interest is also stimulated by importance of this information for correct determination of the characteristics for plasma in thermonuclear (tokamak) reactors, searching new mediums for $\mathrm{X}$-ray range lasers.

In the case of solving collision problems involving multi-electron atomic systems, as well as low-energy processes, etc., the structure of atomic systems should be described on the basis of rigorous methods of quantum theory. As a rule, the Hartree-Fock (HF) or HartreeFock-Slater (HFS) models implemented in the tight-binding approximation were used to describe the wave functions of the bound states of atoms and ions. Another direction is the models of the central potential (model potential, pseudopotential) implemented in the distorted wave approximation (DWA). It should be mentioned the currently widespread and widely used Rmatrix method and its various promising modifications, as well as a generalization of the wellknown Dirac-Fock method to the case of taking into account multipolarity in the corresponding operators (see, e.g. , [1-7]). It should be noted that, depending on the perturbation theory (PT) basis used, different versions of the R-matrix method received the corresponding names. For example, in specific calculations such versions as R-MATR-CI3-5R and R-MATR-41 R-matrix method were used using respectively wave functions in the multiconfiguration approximation, in particular, 5- and 41- configuration wave functions. As numerous applications of the R-matrix method have shown, it has certain advantages in terms of accuracy and consistency over such popular approaches as the first-order PT method, as well as the distorted wave approximation taking into account configuration interaction ( CIDWBA); --- approximation of distorted waves using the HF basis (HF-DWBA), finally, the relativistic approximation of distorted waves with a 1-configuration and multi-configuration wave function of the ground state (SCGS-RDWA, MCGS-RDWA, etc.). Improved models have also appeared in theories of the coupled-channel (VC) type VCDWA (Variational Continuum Distorted Wave), for example, a modification of the Vraun-Scroters type and others (see [1-5]). Various cluster methods have also been widely used (see in more details [1-3,14,15]).

In this paper, we present and use an advanced relativistic energy approach to calculate the electron-ion collision strengths, effective 
collision strengths and the associated cross sections. The relativistic many-body PT is utilised alongside the gauge-invariant scheme to generate an optimal one-electron representation. The calculated effective collision strengths of the Ne-like krypton excitation are listed.

\section{Advanced energy approach to electron collision strengths for atomic systems}

The detailed description of our approach was earlier presented (see, for example, Refs. [7-9,13]). Therefore, below we are limited only by the key points. The generalized relativistic energy approach combined with the RMBPT has been in details described in Refs. [6,14-18]. It generalizes earlier developed energy approach $[6,16]$.

The key idea is in calculating the energy shifts $\mathrm{D} E$ of degenerate states that is connected with the secular matrix $M$ diagonalization $[6,16]$. To construct $M$, one should use the GellMann and Low adiabatic formula for $\mathrm{D} E$. The secular matrix elements are already complex in the PT second order. The whole calculation is reduced to calculation and diagonalization of the complex matrix $M$ and definition of matrix of the coefficients with eigen state vectors $B_{\dot{i}, \dot{v}}^{K}$ $[6,8,9]$.

To calculate all necessary matrix elements one must use the basis's of the 1QP relativistic functions. Within an energy approach the total energy shift of the state is usually presented as $[6,16]$ :

$$
\Delta \mathrm{E}=\operatorname{Re} \Delta \mathrm{E}+\mathrm{i} \Gamma / 2
$$

where $\Gamma$ is interpreted as the level width and decay possibility $P=\Gamma$. The imaginary part of electron energy of the system, which is defined in the lowest PT order as [6]:

$$
\text { m } \Delta E(B)=-\frac{e^{2}}{4 \pi} \underset{\substack{\alpha>n>f \\[\alpha<n \leq f]}}{\sum V_{\alpha n \alpha n}\left|\omega_{\alpha n}\right|},
$$

where $\sum_{\alpha>n>f}$ for electron and for vacancy.

The separated terms of the sum in (3) represent the contributions of different channels. It is known that their adequate description requires using the optimized basis's of wave functions. In [6] it has been proposed "ab initio" optimization principle for construction of cited basis's. It uses a minimization of the gauge dependent multielectron contribution of the lowest QED PT corrections to the radiation widths of atomic levels. This contribution describes collective effects and it is dependent upon the electromagnetic potentials gauge (the gauge non-invariant contribution $\left.\delta \mathrm{E}_{n i n v}\right)$. The minimization of Im$\delta \mathrm{E}_{\text {ninv }}$ leads to integral differential equation, that is numerically solved. In result one can get the optimal one-electron basis of the PT [14,16,17]. It is worth to note that this approach was used under solving of multiple problems of modern atomic , nuclear and molecular physics (see [1425]). The scattered part of $\operatorname{Im} \square E$ appears first in the second order of the atomic PT. The collisional de-excitation cross section is defined as follows $[6,8,9]$ :

$$
\begin{aligned}
& \sigma(K \rightarrow 0)=2 \pi \sum_{j_{i n}, j_{s}}\left(2 j_{x}+1\right) * \\
& *\left\{\sum_{j_{i e}, j_{i v}}<0\left|j_{i n}, j_{\varepsilon}\right| j_{\dot{\varepsilon}}, j_{\dot{v}}, J_{i}>B_{\dot{\dot{v}}, \dot{v}}^{K}\right\}^{2}, \\
& <0\left|j_{i n}, j_{\varepsilon}\right| j_{\dot{e}}, j_{\dot{v}}, J_{i} \geqslant \\
& \sqrt{\left(2 j_{\text {ie }}+1 / 2 j_{i}+1\right)}(-1)^{j_{i e}+1 / 2} \times \sum_{\lambda}(-1)^{\lambda+J_{i}} \times \\
& \times\left\{\delta_{\lambda, J_{i}}\left(2 J_{i}+1\right) Q_{\lambda}(\varepsilon, \dot{e} ; \dot{\boldsymbol{v}}, \dot{\boldsymbol{n}})+,\right. \\
& {\left[\begin{array}{ccc}
j_{\dot{1}} & \ldots j_{\varepsilon} & \ldots J_{i} \\
j_{\dot{e}} & \ldots j_{\dot{v}} & \ldots . . \lambda
\end{array}\right] Q_{\lambda}(\dot{e} ; \dot{n} ; \dot{\boldsymbol{v}}, \mathcal{E})}
\end{aligned}
$$

where $Q$ is the sum of the known Coulomb and Breit matrix elements $[6,14,16]$. The effective collision strength $\Omega(I \rightarrow F)$ is associated with a collisional cross section $\sigma$ as follows (in the Coulomb units):

$$
\sigma(I \rightarrow F)=\Omega(I \rightarrow F) \cdot \pi /
$$

$$
/\left\{\left(2 J_{i}+1\right) \varepsilon_{\dot{i}}[\alpha Z)^{2} \varepsilon_{\dot{i}}+2\right\}
$$

where $Z$ is the nucleus charge and $\alpha$ is the fine structure constant, $\varepsilon_{\text {in }}$ is the incident energy. Further let us firstly consider the Debye shielding model according to Refs. [7-9].

It is known in the classical theory of plasmas developed by Debye-Hückel, the interaction potential between two charged particles is 
modelled by the Yukawa-type potential, which contains the shielding parameter $\mu$. The parameter $\mu$ is connected with the plasma parameters such as the temperature $T$ and the charge density $\mathrm{n}$ as follows: $\mu \sim \sqrt{e^{2} n / k_{B} T}$. Here, as usually, e is the electron charge and $\kappa_{b}$ is the Boltzman constant.

The density $n$ is given as a sum of the electron density $N_{e}$ and ion density $N_{\mathrm{k}}$ of the k-th ion species having the nuclear charge

$$
q_{k}: n=N_{e}+\sum_{k} q_{k}^{2} N_{k} .
$$

It should be noted that indeed the Debye screening for the atomic electrons in the Coulomb field of nuclear charge is well understood due to the presence of the surrounding plasma electrons with high mobility. On the other hand, the contribution due to the Debye screening between electrons would be of smaller magnitude orders.

Majority of the previous works on the spectroscopy study have considered the screening effect only in the electron-nucleus potential where the electron-electron interaction potential is truncated at its first term of the standard exponential expansion for its dominant contribution [3-69]. However, it is also important to take into account the screening in the electronelectron interactions for large plasma strengths to achieve more realistic results in the search for stability of the atomic structure in the plasma environment.

By introducing the Yukawa-type e-N and e-e interaction potentials, an electronic Hamiltonian for $\mathrm{N}$-electron ion in a plasma is in atomic units as follows [7]:

$$
\begin{gathered}
H=\sum_{i}\left[\alpha c p-\beta m c^{2}-Z \exp \left(-\mu r_{i}\right) / r_{i}\right]+ \\
+\sum_{i>j} \frac{\left(1-\alpha_{i} \alpha_{j}\right)}{r_{i j}} \exp \left(-\mu r_{i j}\right)
\end{gathered}
$$

To generate the wave functions basis we use the optimized Dirac-Kohn-Sham potential with one parameter $[14,15]$, which calibrated within the special ab initio procedure within the relativistic energy approach $[16,17]$. All calculations are performed on the basis of the code Superatom-ISAN (version 93).

\section{Results and conclusion}

In Table 1 we present the results of our relativistic calculation (taking into account the exchange and correlation corrections) of the electron collision strengths of excitation the transition between the fine-structure levels (2P $\left.3 / 2-2 \mathrm{P}_{1 / 2}\right)$ of the ground state of F-like ions with $\mathrm{Z}=19-26$.

The energy of the incident electron is $\mathrm{e}_{\text {in }}=0.1294 \times \mathrm{Z}^{2} \mathrm{eV}, \mathrm{T}=\mathrm{z}^{2} \mathrm{keV}$ ( $\mathrm{z}$ is the core charge), $\mathrm{N}_{\mathrm{e}}=10^{18} \mathrm{~cm}^{-3}$. For comparison, in Table 1 there are also listed the calculation results based on the most advanced versions of the R-matrix method, nonrelativistic calculation data in the framework of the energy approach, and also the available experimental data [1-3].

The analysis shows that the presented data are in physically reasonable agreement, however, some difference can be explained by using different relativistic orbital basises and different models for accounting of the plasma screening effect. This circumstance is mainly associated with the correct accounting of relativistic and exchange-correlation effects, using the optimized basis of relativistic orbitals $\left(2 s^{2} 2 p^{5} ; 2 s 2 p^{6} 2 s^{2} 2 p^{4} 31,1=0-2\right)$

Table 1.

The electron collision strengths of excitation the transition between the fine-structure levels $\left(2 P_{3 / 2}-2 P_{1 / 2}\right)$ of the ground state of F-like ions with $Z=19-26$

\begin{tabular}{|c|c|c|}
\hline Ion & $\begin{array}{c}\text { ICFT } \\
\text { R-matrix }\end{array}$ & $\begin{array}{c}\text { LS+JAJOM } \\
\text { R-matrix }\end{array}$ \\
\hline Ar X & 0.582 & 0.420 \\
\hline Ca XII & 0.162 & 0.160 \\
\hline Ti XIV & 0.225 & 0.220 \\
\hline Cr XVI & 0.112 & 0.100 \\
\hline Fe XVIII & 0.132 & 0.110 \\
\hline Ion & $\begin{array}{c}\text { Our } \\
\text { data }\end{array}$ & $\begin{array}{c}\text { Exp. } \\
{[6]}\end{array}$ \\
\hline Ar X & 0.492 & 0.49 \\
\hline Ca XII & 0.159 & - \\
\hline Ti XIV & 0.252 & - \\
\hline Cr XVI & 0.142 & - \\
\hline Fe XVIII & 0.148 & 0.15 \\
\hline
\end{tabular}

and, to a lesser extent, taking into account the effect of the plasma environment. 
The electron-ion collision characteristics for Be-like ions are of great interest for applications such as the diagnosis of astrophysical, laboratory, and thermonuclear plasmas, as well as EBIT plasmas (see, for example, [4,5]). In the latter case, the characteristic values of electron density turn out to be significantly (several orders of magnitude) less than those considered above $\left(10^{15}-10^{17}\right)$. In particular, the so-called MEIBEL (the merged electron-ion beams energy-loss) experiment (1999), the results of which for a Be-like oxygen ion are presented in Fig. 1. In this figure there also listed the cross section $\left(10^{-16} \mathrm{~cm}^{3}\right)$ of the electron-collision excitation of the $\left[2 s^{2}{ }^{1} \mathrm{~S}-\left(2 \mathrm{~s} 2 \mathrm{p}^{1} \mathrm{P}\right)\right]$ transition in the spectra of Be-like oxygen together with the data from an alternative 3-configuration R-matrix calculation [4]. At energies below $20 \mathrm{eV}$ there is the reasonable agreement between the theoretical and experimental, but, above $20 \mathrm{eV}$ there is a discrepancy, which is due to different degrees of allowance for correlation effects (interaction of configurations) due to the difference in the bases used.

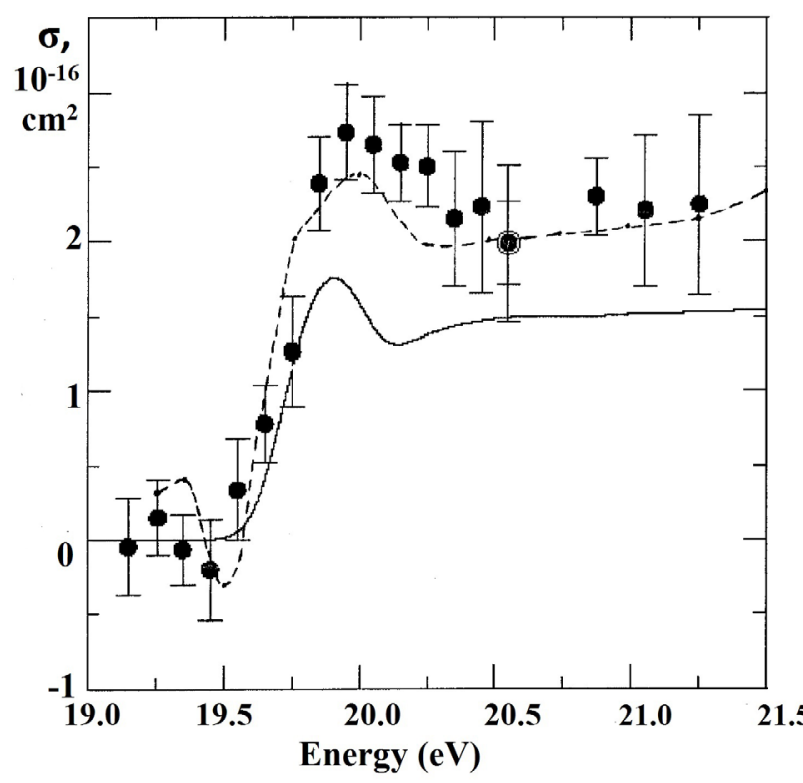

Fig.1. Cross section for electron-collision excitation of the $\left[2 s^{2}{ }^{1} S-\left(2 s 2 p{ }^{1} P\right)\right]$ transition in the spectra of $\mathrm{B}$-like $\mathrm{O}^{4+}$ : Experiment $\mathrm{MEI}-$ BEL - points; Theory: R-matrix - solid line; our theory - dashed line.

\section{References}

1. Badnell, N.R. Calculations for electron-ion collisions and photoionization processes for plasma modeling. J. Phys.: Conf. Ser. 2007, 88, 012070 .

2. Griffin, D.C., Balance, C., Mitnik, D., Berengut, J.C. Dirac R-matrix calculations of electron-impact excitation of neon-like krypton. J. Phys. B: At. Mol. Opt. Phys. 2008, 41, 215201.

3. Yongqiang, Li; Jianhua, Wu; Yong, Hou, Jianmin Yuan. Influence of hot and dense plasmas on energy levels and oscillator strengths of ions: Be-like ions for $Z=26-36, J$. Phys. B: At. Mol. Opt. Phys. 2008, 41, 145002.

4. Bannister, M. E., Djurić, N., Woitke, O., Dunn, G., Chung, Y. -S, Smith, A. C. H., Wallbank, B., Berrington, K. A. Absolute cross-sections for near-threshold electronimpact excitation of Be-like $\mathrm{C}^{2+}, \mathrm{N}^{3+}, \mathrm{O}^{4+}$. Int. J. Mass Spectr. 1999, 192, 39-48.

5. Smith, A. C. H., Bannister, M. E., Chung, Y. -S, Djuri,ć N., Dunn, G. H., Wallbank, B., Woitke, O. Near-threshold Electron-impact Excitation of Multiply-charged Be-like Ions. Phys.Scr. 1999, T80, 283-287.

6. Ivanov, L.N.; Ivanova, E.P.; Knight, L. Energy approach to consistent QED theory for calculation of electron-collision strengths: Ne-like ions. Phys. Rev. A. 1993, 48, 43654374.

7. Buyadzhi, V.V. Laser multiphoton spectroscopy of atom embedded in Debye plasmas: multiphoton resonances and transitions. Photoelectronics. 2015, 24, 128-133.

8. Buyadzhi, V.V.; Chernyakova, Yu.G.; Smirnov, A.V.; Tkach, T.B. Electron-collisional spectroscopy of atoms and ions in plasma: Be-like ions. Photoelectronics. 2016, 25, 97-101.

9. Buyadzhi, V.; Chernyakova, Yu.; Antoshkina, O.; Tkach, T. Spectroscopy of multicharged ions in plasmas: Oscillator strengths of Be-like ion Fe. Photoelectronics. 2017, 26, 94-102.

10. Glushkov, A.V.; Malinovskaya, S.V.; Prepelitsa, G.P.; Ignatenko, V. Manifestation of the new laser-electron nuclear spectral effects in the thermalized plasma: QED theory 
of co-operative laser-electron-nuclear processes. J. Phys.: Conf. Ser. 2005, 11, 199206.

11. Glushkov, A.V.; Malinovskaya, S.V.; Chernyakova Y.G.; Svinarenko, A.A. Cooperative laser-electron-nuclear processes: QED calculation of electron satellites spectra for multi-charged ion in laser field. Int. Journ. Quant. Chem. 2004, 99, 889-893.

12. Glushkov, A.V.; Malinovskaya, S.V.; Loboda, A.V.; Shpinareva, I.M.; Gurnitskaya, E.P.; Korchevsky, D.A. Diagnostics of the collisionally pumped plasma and search of the optimal plasma parameters of x-ray lasing: calculation of electron-collision strengths and rate coefficients for Ne-like plasma. J. Phys.: Conf. Ser. 2005, 11, 188198.

13. Glushkov, A.V.; Ambrosov, S.V.; Loboda, A.V.; Gurnitskaya, E.P.; Prepelitsa, G.P. Consistent QED approach to calculation of electron-collision excitation cross sections and strengths: Ne-like ions. Int. J. Quantum Chem. 2005, 104, 562-569.

14. Glushkov, A.V. Relativistic Quantum theory. Quantum mechanics of atomic systems; Astroprint: Odessa, 2008.

15. Khetselius, O.Yu. Hyperfine structure of atomic spectra. Astroprint: Odessa, 2008.

16. Glushkov, A.V.; Ivanov, L.N.; Ivanova, E.P. Autoionization Phenomena in Atoms. Moscow Univ. Press, 1986, 58-160

17. Glushkov, A.; Ivanov, L. Radiation decay of atomic states: atomic residue polarization and gauge noninvariant contributions. Phys. Lett. A 1992, 170, 33.
18. Glushkov, A.V. Spectroscopy of atom and nucleus in a strong laser field: Stark effect and multiphoton resonances. J. Phys.: Conf. Ser. 2014, 548, 012020

19. Khetselius, O.Yu. Spectroscopy of cooperative electron-gamma-nuclear processes in heavy atoms: NEET effect. J. Phys.: Conf. Ser. 2012, 397, 012012.

20. Glushkov A.V.; Ivanov, L.N. DC strongfield Stark effect: consistent quantum-mechanical approach. J. Phys. B: At. Mol. Opt. Phys. 1993, 26, L379-386.

21. Ignatenko, A.V. Probabilities of the radiative transitions between Stark sublevels in spectrum of atom in an DC electric field: New approach. Photoelectronics, 2007, 16, 71-74.

22. Glushkov, A.V.; Ambrosov, S.V.; Ignatenko, A.V. Non-hydrogenic atoms and WannierMott excitons in a DC electric field: Photoionization, Stark effect, Resonances in ionization continuum and stochasticity. Photoelectronics, 2001, 10, 103-106.

23. Glushkov A., Ternovsky V., Buyadzhi V., Prepelitsa G., Geometry of a relativistic quantum chaos: New approach to dynamics of quantum systems in electromagnetic field and uniformity and charm of a chaos. Proc. Intern. Geom. Center. 2014, 7(4), 60-71.

24. Khetselius, O.Yu. Relativistic perturbation theory calculation of the hyperfine structure parameters for some heavy-element isotopes. Int. Journ.Quant.Chem. 2009, 109, 3330-3335.

25. Khetselius, O. Hyperfine structure of radium. Photoelectronic. 2005, 14, 83-85. 
PACS 31.15.-p

V. V. Buyadzhi

\section{ELECTRON-COLLISIONAL SPECTROSCOPY OF ATOMS AND IONS: ADVANCED ENERGY APPROACH}

Summary. An advanced relativistic energy approach combined with a scattering theory is used to calculate the electron-collision excitation cross-sections, collision strengths for a number of multicharged ions. The relativistic many-body perturbation theory is used alongside the gauge-invariant scheme to generate an optimal Dirac-Kohn-Sham- Debye-Hückel one-electron representation. The results of relativistic calculation (taking into account the exchange and correlation corrections) of the electron-collision cross-sections (strengths) of excitation of the transition between the finestructure levels $\left(2 \mathrm{P}_{3 / 2}-2 \mathrm{P}_{1 / 2}\right)$ of the ground state of F-like ions with $\mathrm{Z}=19-26$ and of the $\left[2 \mathrm{~s}^{2}{ }^{1} \mathrm{~S}\right.$ $\left.-\left(2 \mathrm{~s} 2 \mathrm{p}^{1} \mathrm{P}\right)\right]$ transition in the $\mathrm{B}$-like $\mathrm{O}^{4+}$ are presented and analysed

Key words: spectroscopy of ions, relativistic energy approach, collision cross-sections

PACS 31.15.-p

$$
\text { В. В. Буяджи }
$$

\section{ЭЛЕКТРОН-СТОЛКНОВИТЕЛЬНАЯ СПЕКТРОСКОПИЯ АТОМОВ И ИОНОВ: РЕЛЯТИВИСТСКИЙ ЭНЕРГЕТИЧЕСКИЙ ПОДХОД}

Резюме. Эффективный релятивистский энергетический подход в сочетании с теорией столкновений используется для расчета сечений электрон-столкновительного возбуждения, сил столкновений для ряда многозарядных ионов. Релятивистская теория многочастичная теория возмущений наряду с эффективной калибровочно-инвариантной схемой используется для генерации оптимального одноэлектронного представления Дирака-Кона-ШамаДебая-Хюккеля. Представлены и анализируются результаты расчета (с учетом обменных и корреляционных поправок) сечений столкновительного возбуждения перехода между уровнями тонкой структуры $\left(2 \mathrm{P}_{3 / 2}-2 \mathrm{P}_{1 / 2}\right) \mathrm{F}$-подобных ионов и возбуждения перехода $\left[2 \mathrm{~s}^{2}{ }^{1} \mathrm{~S}\right.$ $\left.-\left(2 \mathrm{~s} 2 \mathrm{p}^{1} \mathrm{P}\right)\right]$ в Ве-подобном $\mathrm{O}^{4+}$.

Ключевые слова: спектроскопия ионов, энергетический подход, сечения столкновений

PACS 31.15.-p

В. В. Буяджи

\section{СПЕКТРОСКОПІЯ ЗА РАХУНОК ЕЛЕКТРОННИХ ЗІТКНЕНЬ АТОМІВ І ИОНОВ: РЕЛЯТИВІСТСЬКИЙ ЕНЕРГЕТИЧНИЙ ПІДХІД}

Резюме. Ефективний релятивістський енергетичний підхід в поєднанні з теорією зіткнень використовується для розрахунку перетинів електрон-зіткнень збудження, сил зіткнень для ряду багатозарядних іонів. Релятивістська теорія багаточастинкових теорія збурень використовується для генерації оптимального одноелектронного уявлення Дірака-Кона-Шама-Дебая-Хюккеля. Представлені і аналізуються результати розрахунку (з урахуванням обмінних і кореляційних поправок) перерізів збудження за рахунок зіткнення переходу між рівнями тонкої структури (2P $\left.\mathrm{P}_{3 / 2}-2 \mathrm{P}_{1 / 2}\right) \mathrm{F}$-подібних іонів і збудження переходу $\left[2 \mathrm{~s}^{2}{ }^{1} \mathrm{~S}-\left(2 \mathrm{~s} 2 \mathrm{p}{ }^{1} \mathrm{P}\right)\right]$ в Beподібному $\mathrm{O}^{4+}$.

Ключові слова: спектроскопія іонів, енергетичний підхід, перерізи зіткнень 